though in eastern Europe it still appears to be in progress (Eiben, 1972).

\section{References}

Brundtland, G. H., and Walløe, L. (1973). Nature, 241, 478.
Dann, T. C., and Roberts, D. F. (1969). British fournal of Preventive and Social Medicine, 23, 65 .

Eiben, O. G. (1972). Anthropologischer Anzeiger, 33, 205.
Roberts, D. F., and Dann, T. C. (1967). British fournal of Preventive and Social Medicine, 21, 170 .

Roberts, D. F., Rozner, L. M., and Swan, A. V. (1971). Acta Paediatrica Scandinavica, 60, 158 .

Tanner, J. M. (1955). Growth at Adolescence, 1st edn. Oxford, Blackwell Scientific

Tanner, J. M. (1962). Growth at Adolescence, 2nd edn. Oxford, Blackwell Scientific.

Tanner, J. M. (1965). In Biological Aspects of Social Problems, ed. J. E. Meade and A. S. Parkes, Edinburgh, Oliver and Boyd.

Zacharias, L., Wurtman, R. J., and Schatzoff, M. (1970). American fournal of Obstetrics and Gynaecology, 108, 833.

\title{
Renal Puncture in Infancy
}

\author{
H. M. SAXTON, J. S. CAMERON, C. CHANTLER, C. S. OGG
}

British Medical fournal, 1973, 3, 267-270

\section{Summary}

Renal puncture was used in the diagnosis of five infants with suspected cystic disease of the kidney. This technique is simple and it may provide information that may otherwise be difficult to obtain.

\section{Introduction}

The use of diagnostic renal puncture in children and adults is now well established. Apart from puncture for renal biopsy the commonest use is in the diagnosis of simple renal cysts (Lindblom, 1946; Sherwood and Stevenson, 1971). It has also been used to confirm the presence and define the nature of obstruction of the upper urinary tract (Weens and Florence, 1954; Wickbom, 1954; Sherwood and Stevenson, 1972) and to produce temporary drainage of an obstructed kidney (Ogg et al., 1969; Saxton et al., 1972). While the use of renal puncture for antegrade pyelography during infancy has been described (Lalli, 1969) it is still uncommon, and renal puncture does not so far appear to have been used in the diagnosis of cystic disease sof the kidney at this age. We are therefore presenting our experience with five infants in whom renal puncture was used as a diagnostic aid. Four cases suffered from renal failure and a fifth had a non-functioning kidney.

\section{Case Reports}

Case 1.-Female infant born at full term by a normal delivery. Did not cry at birth and was cyanosed. Chest $x$-ray picture showed a left pneumothorax which was aspirated. Seven days after birth the blood urea was found to be $168 \mathrm{mg} / 100 \mathrm{ml}$ and she was transferred to Guy's Hospital. Her head was small, but the ears were normal. There was oedema of the lower limbs, and the kidneys were easily palpable. Intravenous urography showed no excretion of contrast, but there was a vaguely defined right kidney. Renal puncture on the left revealed multiple cysts, some intercommunicating (fig. 1). No filling of the collecting system was achieved. A diagnosis of multicystic renal disease was made. At no stage was any urine passed. The blood urea rose, and two days after admission she died. Necropsy showed \footnotetext{
Departments of Radiology, Medicine, and Paediatrics, Guy's
Hospital, London SE1 9RT

H. M. SAXTON, F.R.C.P., F.F.R., Consultant Radiologist

J. S. CAMERON, M.D., F.R.C.P., Senior lecturer in Medicine and Renal Physician

C. CHANTLER, M.D., M.R.C.P., Consultant Paediatrician

C. S. OGG, M.D., M.R.C.P., Renal Physician
}

changes in the lungs consistent with hyaline membrane disease. There were no cysts in the lungs or liver. The kidneys were large with numerous cysts. Some parenchyma was found between the cysts but no calyces or papillae were seen. Microscopy showed that the renal tissue contained cartilage and metanephric tubular elements. Many tubules were dilated. The lower ureters were normal but the upper ureters were dilated with frail transparent walls.

Case 2.-Male infant. Admitted 14 hours after birth because of difficulty with breathing and cyanotic attacks. He was cyanosed with bilaterally diminished air entry and was found to have bilateral pneumothoraces. There was a single palmar crease and widely splayed toes. A prominent medial epicanthic fold was noted extending down-

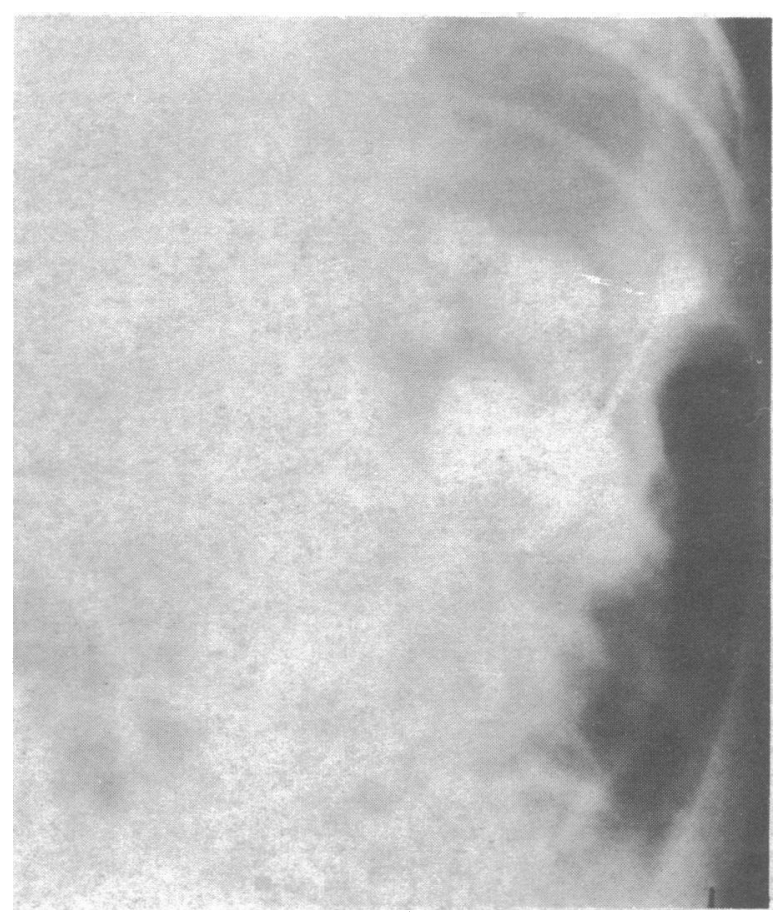

FIG. 1-Case 1. Left renal puncture with injection of contrast. Injection into two cystic areas has produced filling of multiple renal cysts due to intercommunication between cysts.

wards beneath the eye on to the upper cheek. The ears were normal. A right-sided intercostal drain was inserted. During the next 36 hours he did not pass urine, and intravenous urography two days after admission showed no excretion of contrast and a faint renal outline on the right side. Blood urea at this stage was $66 \mathrm{mg} / 100 \mathrm{ml}$. An attempt was then made to needle the kidneys, but at no stage was a 

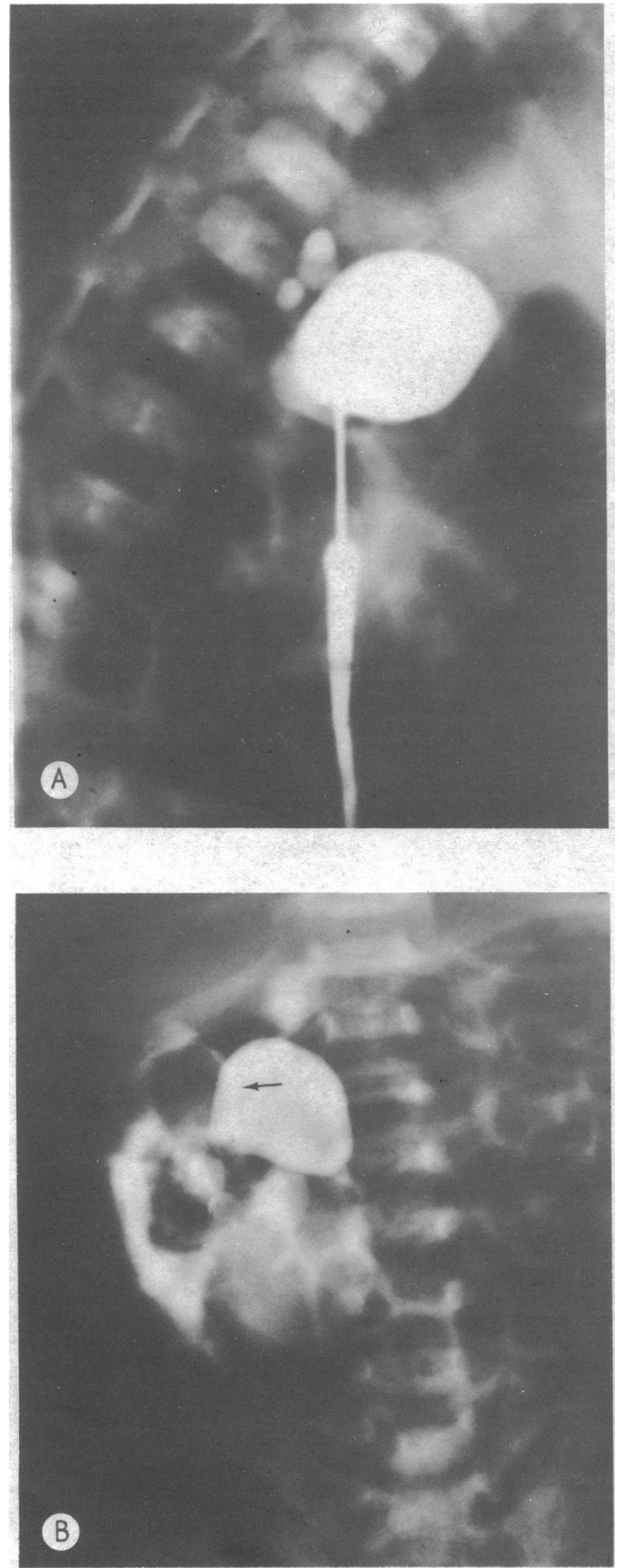

FIG. 2-Case 3. A. Lateral film after introduction of needle into an upper pole cyst. Other cysts have also filled from this injection. B. Anteroposterior Arrow indicates negative shadow of a cyst lying between others which have been opacified. respiratory "swing" obtained on either side and no fluid was withdrawn. Subsequently a radio-Hippuran scan showed no uptake in the region of the kidneys. His blood urea continued to rise, reaching $380 \mathrm{mg} / 100 \mathrm{ml}$, and 24 days after birth he died. At necropsy the lung showed only patchy collapse and no cysts or other abnormality. The liver and pancreas were also free of cysts. The right kidney showed numerous fluid-filled cysts. The left was smaller with no cysts. Both were found to be dysplastic with fibrous tissue, epithelial-lined tubules surrounded by loose mesenchymal tissue, occasional primitive glomeruli, and rare islands of primitive cartilage. On both sides the ureters were atretic.

Case 3.-Male infant. Normal delivery at 38 weeks. Birth weight $4 \mathrm{lb} 12 \mathrm{oz}(2,154 \mathrm{~g})$. Routine examination showed a palpable mass in the right loin and intravenous urography showed a normal kidney on the left side but no visualization of the right kidney. There were possible cystic translucencies on the tomograms on the right side. Subsequent renal puncture showed multiple intercommunicating cysts on the right side (fig. 2) with translucencies due to further cysts partially outlined by the contrast in adjacent cysts which had been injected. Blood urea was $42 \mathrm{mg} / \mathrm{ml}$. It was decided that no operation was necessary at this stage and the child has been followed up. He has made satisfactory progress. Repeat intravenous urography at 2 years again showed a normal left kidney with no evidence of any excretion of contrast on the right side.

Case 4.-Male infant aged 3 months. Admitted to hospital with history of anuria and fits after an attack of gastroenteritis. He was slightly oedematous with bilaterally palpable kidneys. The blood urea was $170 \mathrm{mg} / 100 \mathrm{ml}$. A diagnosis of renal vein thrombosis or acute tubular necrosis was made and peritoneal dialysis was begun. After a week he began to pass urine and dialysis was discontinued. The blood urea stabilized at $100 \mathrm{mg} / 100 \mathrm{ml}$ and intravenous urography was undertaken. The kidneys were poorly shown, but there was an appearance suggesting areas of translucency within the nephrogram raising the possibility of cystic kidneys. Though this was felt to be unlikely it was decided to attempt diagnostic puncture before renal biopsy. The needle entered a normal collecting system; no cysts were found in the parenchyma. Subsequent needle biopsy showed areas of infarction confirming the probable diagnosis of renal vein thrombosis. Later $x$-ray pictures showed progressive calcification in the renal substance with gradual contraction of the kidneys. He developed intractable hypertension, acidosis, and a salt-losing state, and nine weeks after admission he died. Necropsy showed contracted calcified kidneys with organized thrombus in the renal vein.

Case 5.-Male infant. Full-term normal delivery. Noted to have low-set ears but no other abnormality found. During the first week of life he became jaundiced with a bilirubin of $10.6 \mathrm{mg} / 100 \mathrm{ml}$. At 11 days the blood urea was found to be $136 \mathrm{mg} / 100 \mathrm{ml}$ and the serum

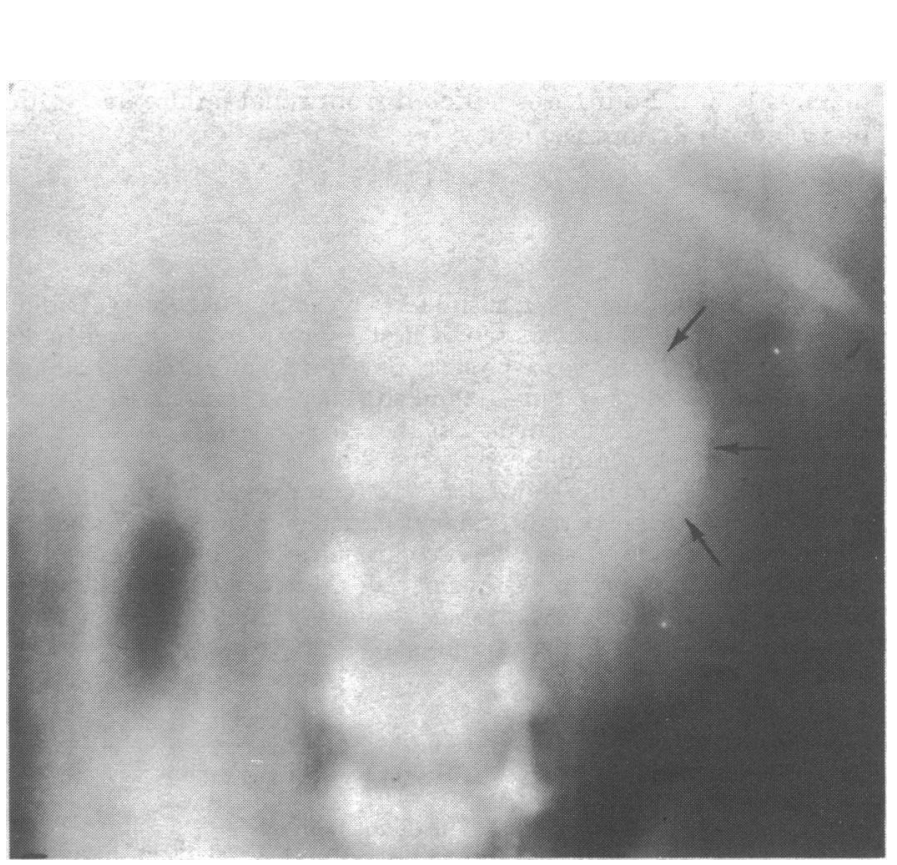

FIG. 3-Case 5. One-hour intravenous urography showing area of opacification on left side due to a dilated renal pelvis. 
potassium $7 \cdot 1 \mathrm{mEq} / 1$. Intravenous urography showed no evidence of excretion on the right, while on the left there was a small kidney with gradual appearance of contrast in the region of a probable dilated pelvis (fig. 3). He was provisionally diagnosed as having dysplastic kidney with hydronephrosis. Renal puncture was performed to confirm the presence of obstruction. This showed a pelviureteric obstruction with a normal ureter (fig. 4). A catheter was introduced into the renal pelvis and was left draining. About $300 \mathrm{ml}$ urine drained daily and the blood urea fell to $100 \mathrm{mg} / 100 \mathrm{ml}$ and the serum potassium to $5.5 \mathrm{mEq} / \mathrm{l}$. Three days later the left kidney was explored. It was found to be hypoplastic with multiple cysts. The pelviureteric narrowing was confirmed and a Hynes-Anderson pyeloplasty was performed. No urine was passed per urethram after the operation. The abdomen gradually became distended and 20 days after operation he died. Permission for necropsy was refused.

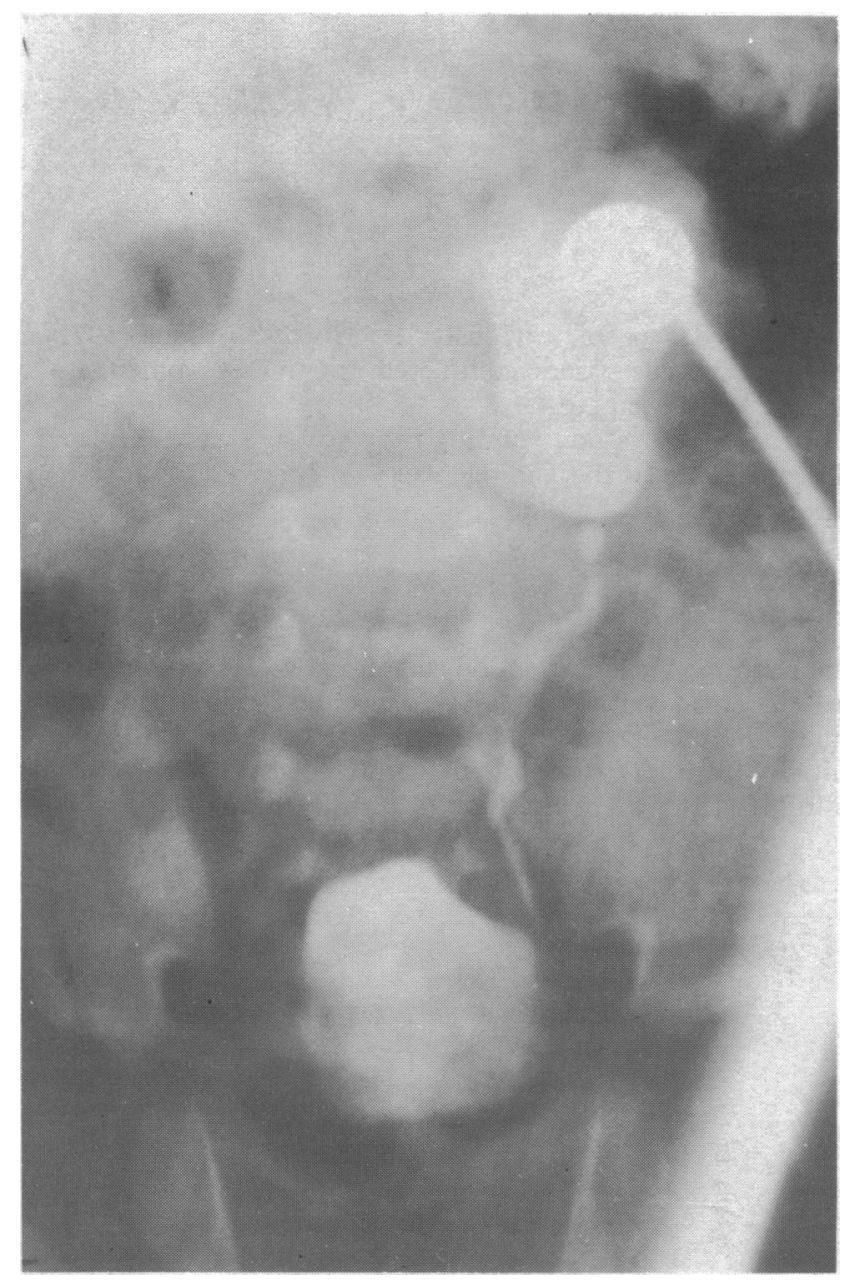

FIG. 4-Case 5. Renal puncture showing pelvic dilatation and pelviureteric obstruction with a normal ureter and bladder. This pelvis was subsequently drained by a catheter introduced percutaneously.

\section{Technique for Puncture}

The likely position of any renal shadows is carefully assessed from the available films and their relation to spine, ribs, and pelvic crest is noted. The infant is sedated if necessary, and in cases with a unilaterally non-visualized kidney contrast is given to opacify the normal side. The infant is placed prone on the fluoroscope table, the skin cleansed, and using the landmarks already mentioned a point is selected for puncture. Local anaesthetic is infiltrated and a No. 1 disposable needle $(21 \mathrm{G}, 38 \mathrm{~mm})$ is advanced gradually down until a respiratory "swing" develops. Failing this the needle is withdrawn and readvanced in whichever direction seems appropriate. When the needle is thought to lie in the kidney, whether or not fluid emerges, a flexible connecting tubing is attached and gentle suction applied as the needle is withdrawn. If fluid is aspirated some is taken for examination, and contrast - for example, methyglucamine iothalamate (Conray 280) - is injected under screen control. There are three main possibilities:

(1) The needle has entered a normal collecting system. This is immediately obvious and rules out multicystic disease or hydronephrosis. Polycystic disease is still a possibility, but it should be possible to exclude this by aspirating as the needle is withdrawn.

(2) The needle has entered a cyst. In our two cases of multicystic disease there was some intercommunication between cysts. The picture is unlike that seen in hydronephrosis where contrast tends to run into the pelvis, but does not pass readily into other calyces until the pelvis has been filled. The translucency from contrast around the non-opacified cysts is also evidence of cystic disease.

(3) The needle has entered a hydronephrotic calyx or pelvis. As already noted the contrast runs towards the pelviureteric region and may enter the ureter.

\section{Discussion}

It is of some interest that our two cases with multicystic kidneys presented with pneumothoraces. The association between pneumothorax or pneumomediastinum and urinary tract malformations has been reviewed recently by Renert et al. (1972) and by Stern et al. (1972). They add in all 18 cases to the previously recorded literature and both papers stress that unexplained pneumothorax or pneumomediastinum occurring in neonates should arouse a strong suspicion of associated urinary tract anomalies. The cases described by Stern and his co-workers comprised seven with renal agenesis or dysplasia while two had cystic dysplasia. In contrast Renert and his colleagues stress the association with obstructive malformations and point out the frequency of oligohydramnios in such cases. Of the cases described by Stern et al. seven had Potter's facies but in those presented by Renert et al. an abnormal facies is mentioned in only three, and it is clear that facial abnormalities are not an invariable part of this association.

A further point of interest is that some degree of intercommunication appeared to exist between these cysts. This is an unexpected finding which may bear on the site of origin of such cysts since it is only in the collecting tubules that there is intercommunication between nephrons.

The main purpose of this paper is to point out the possible uses for renal puncture in the first year of life. Though improvements in urography have increased its diagnostic accuracy in cases of renal failure or non-visualized kidney there may be considerable difficulty in obtaining satisfactory radiographs of the kidney in infancy and particularly in the neonatal period. Respiratory movement, lack of perirenal fat, and distension of the small bowel by gas all tend to obscure already faint shadows of poorly opacified parenchyma or collecting system. At this age retrograde pyelography is technically difficult and sometimes impossible. Renal arteriography is most readily performed via the umbilical artery in the first five days of life (Philp et al., 1973). Though feasible later in infancy it is not without risk and may not yield positive information. The most hopeful alternative means of diagnosis is diagnostic ultrasound (Lyons et al., 1972). This shows considerable potential in dealing with these problems, but it is not yet generally available. It is therefore natural to use renal puncture in cases presenting diagnostic difficulty particularly when renal cystic disease is suspected. The technique is simple, the main problem being to determine the whereabouts of the kidney. The failure of puncture in case 2 must presumably have been due to faulty positioning of the needle since attempts were made to puncture the kidney on both sides, and though there were no cysts on the left there were numerous large cysts on the right. It may well be that ultrasonic location 
of the kidney will render puncture more accurate in future. In our remaining cases puncture was able to confirm the presence of multiple cysts in two cases (one unilateral), to exclude cystic disease in one case, and to confirm the presence of hydronephrosis in one. In the latter case a period of drainage through a tube introduced percutaneously improved the child's condition sufficiently to render him fit for operation. Our experience therefore indicates that in suitable cases diagnostic puncture is a simple method of providing information which may otherwise be difficult to obtain.

We are grateful to our colleagues Drs. Philip Evans, Michael Joseph, and Leo Stimmler for allowing us to report these cases who were admitted under their care.

\section{References}

Lalli, A. F. (1969). Pediatrics, 44, 1016.

Lindblom, K. (1946). Acta Radiologica, 27, 66.

Ogg, C. S., Saxton, H. M., and Cameron, J. S. (1969). British Medical fournal, 4, 657 .

Philp, T., Cockburn, F., and Anderson, J. M. (1973). Clinical Radiology,

Renert, W. A., Berdon, W. E., Baker, D. H., and Rose, J. S. (1972). Radio$\log y, 105,97$

Saxton, H. M., Ogg, C. S., and Cameron, J. S. (1972). British Medical Bulletin, 28, 210

Sherwood, T., and Stevenson, J. J. (1971). Clinical Radiology, 22, 180.

Sherwood, T., and Stevenson, J. J. (1972). British fournal of Radiology, 45, 812.

Stern, L., Fletcher, B. B., Dunbar, J. S., Levant, M. N., and Fawcett, J. S. (1972). American fournal of Roentgenology, 116, 785.

Weens, H. S., and Florence, T. J. (1954). Fournal of Urology, 72, 589.

Wickbom, I. (1954). Acta Radiologica, 41, 505.

\title{
Regular Decline in Physical Working Capacity with Age
}

\author{
L. E. BÖTTIGER
}

British Medical fournal, 1973, 3, 270-271

\section{Summary}

Analysis of the results of two cross country races, one on foot and one on skis, in which nearly 10,000 men competed showed that performance is very closely matched with age. There is a decrease of $5-10 \%$ in the performance every 10 years from optimum age for the event. This optimum varies for different types of physical activity. Studies in a small group of women showed similar variations.

\section{Introduction}

Information about the value of regular physical activity in Sweden has led to mass participation in various athletic activities such as cross-country running and skiing. In some of the events as many as 10,000 entrants-that is, one Swedish man out of every 500-have been registered. Most of the participants are not professional athletes, but in fact constitute a cross-section of the population with regard to age, occupation, education, etc.

This development is largely a positive one, but of course there are also certain risks involved, mainly that people overestimate their physical capacity, which may have serious medical consequences. It is thus important to study the alteration of physical working capacity with age. This has been done for the Vasa ski race (Böttiger, 1971). A new study of a cross-country running event, however, made the combined results more significant and worthy of a further report.

\section{Material}

The Lidingö cross-country race is run over a distance of $30 \mathrm{~km}$ (19 miles). In 1972 about 2,200 male runners were registered as entrants, 1,911 of whom completed the race. Ninety women ran a shorter distance ( $16 \mathrm{~km}, 10$ miles).

The Vasa cross-country ski race over a distance of $87 \mathrm{~km}$

\footnotetext{
Department of Internal Medicine, Karolinska Hospital, Stockholm
Sweden

L. E. BÖTTIGER, M.D., Professor of Medicine
}

(54 miles) has been previously described (Böttiger, 1971). In 1970 7,625 male skiers completed the race-women are not allowed to participate.

In the present study running time and age were recorded for all participants in the Lidingö race, and conventional statistical methods have been used.

\section{Results}

The running times in relation to age are shown in figs. 1 and 2 , and statistical variables and age distribution are given in the table. The results within each age group were found to be essentially normally distributed, with a slight tendency towards tailing on the side of the longest running times.

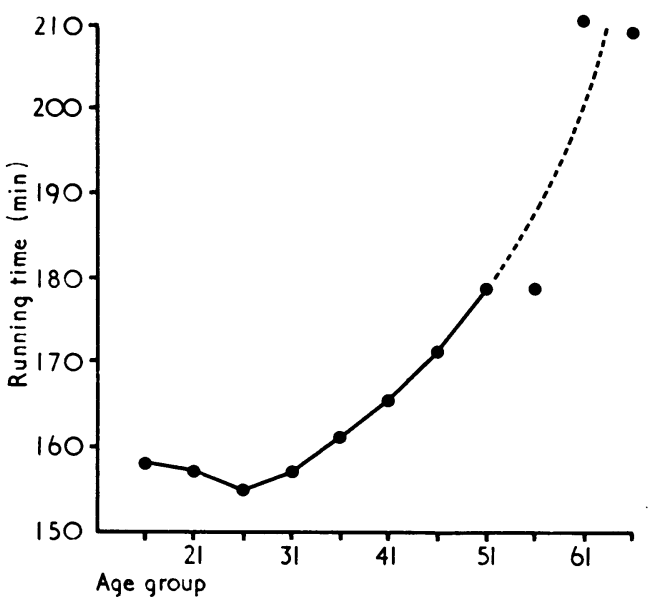

FIG. 1-Running times in relation to age. Mean times of each five-year group of men.

The relative results in different age groups for men, calculated as a percentage of the best results, are given in fig. 3 for the Vasa as well as for the Lidingö race.

It is evident that the age-bound variation in physical performing capacity is a regular phenomenon. Though the best results in the two types of activity are obtained at a some- 